\title{
Desafios da intersetorialidade nas políticas públicas de saúde e assistência social: uma revisão do estado da arte
}

I ${ }^{1}$ Michelly Eustáquia do Carmo, ${ }^{2}$ Francini Lube Guizardi I

Resumo: Intersetorialidade é um tema muito discutido, mas não os desafios para sua execução entre as políticas públicas de saúde e assistência social. Com a revisão do estado da arte da temática, debatemos neste artigo os principais desafios do trabalho intersetorial entre tais políticas. As categorias polissemia, ciclo de políticas, burocracia, participação social e equidade norteiam o debate com o método da análise interpretativa. Ainda que possa responder às demandas sociais multifacetadas, evitando prejuízos da fragmentação setorial, a intersetorialidade não é solução para todo problema de gestão pública. Já sua relação com a participação popular pode conferir maior equidade nas ofertas das políticas analisadas.

> Palavras-chave: intersetorialidade; saúde; assistência social; desafios; equidade.
1 Ministério do Desenvolvimento Social, Departamento de Proteção Social Básica. BrasíliaDF, Brasil (michelly.carmo@mds. gov.br).

${ }^{2}$ Escola de Governo, Fundação Oswaldo Cruz. Brasília-DF, Brasil (flguizardi@gmail.com).

Recebido em: 13/06/2017 Aprovado em: 31/10/2017 
A Constituição Federal de 1988 introduziu significativos avanços ao ordenamento legal brasileiro, ampliando direitos e corrigindo iniquidades. Tais avanços tiveram particular relevância no âmbito da Seguridade Social, conceituando um modelo de proteção social até então ausente na legislação e nos modelos nacionais de proteção pública.

Com esta abordagem, o Estado brasileiro passou a reconhecer a Seguridade Social e, consequentemente, as políticas públicas de Saúde e de Assistência Social, segundo o art. 194, caput da Constituição Federal, como "um conjunto integrado de iniciativas dos poderes públicos e da sociedade, destinado a assegurar os direitos relativos à saúde, à previdência e à assistência social” (BRASIL, 2016). A Seguridade Social, nessa direção, passou a ter conotaçáo ampliada ao unir açôes distributivas com a tradicional prática contributiva previdenciária, adotada pelo Estado desde os anos 1930 (PEREIRA, 2002). O direito universal à saúde a ser garantido pelo Estado e a positivação da assistência social como política pública de direitos na Constituição de 1988 representaram avanços normativos em relaçáo à lógica de seguro que pautava o atendimento à populaçáo nestas áreas. A previdência social, todavia, permaneceu sob essa lógica, distanciandose tanto das características de política social quanto das demais políticas que compóem o tripé da seguridade social brasileira (MONNERAT; SOUZA, 2011; BOSCHETTI, 2003).

Com isso se define que o Sistema de Seguridade Social, instituído pela Carta Magna de 1988, pretendeu incorporar três políticas sociais em torno de dois eixos diferenciados: um contributivo, representado pela previdência social, e outro não contributivo e distributivo, representado pelas políticas de Saúde e de Assistência Social, que, por sua vez, foram organizadas por meio de sistemas únicos: o Sistema Único de Saúde (SUS) e o Sistema Único de Assistência Social (SUAS) e tiveram, em suas respectivas Leis Orgânicas, a inclusão da diretriz e do objetivo de atuação intersetorial (BRASIL, 1990; 1993).

No entanto, em observância ao processo de implementaçáo dos serviços públicos após a Constituiçáa Federal de 1988, no âmbito do eixo distributivo Saúde e Assistência Social, identifica-se a temática da intersetorialidade e da articulação como elementos ainda desafiadores, uma vez que, mesmo sendo elementar aos objetivos da gestão pública, não se materializam ou ganham sua 
amplitude como pensado e proposto nos marcos regulatórios da seguridade social e de cada política em análise.

Assim, a consolidação da intersetorialidade das políticas públicas passou a ganhar valor à medida que não se observava a eficiência, a efetividade e a eficácia esperadas na implementação das políticas setoriais, primordialmente no que se refere ao atendimento das demandas da população e aos recursos disponibilizados para sua execução (NASCIMENTO, 2010). Com esse entendimento, o eixo da intersetorialidade ganhou repercussão no processo de implementação das políticas setoriais, visando a sua efetividade e menor custo de execução por meio da articulação entre instituiçóes governamentais e entre essas e a sociedade civil, no intuito ainda de enfrentar a complexidade dos problemas sociais contemporâneos (REZENDE; BAPTISTA; AMÂNCIO FILHO, 2015; COMERLATO et al., 2007; MONNERAT; SOUZA, 2009).

Embora a conjuntura político-econômica em que se processou a implantação das mudanças constitucionais e a implementação das políticas públicas setoriais tenha sido marcada por disputas ideológicas, é imprescindível assinalar que as trajetórias institucionais e o legado político e técnico das políticas de Saúde e Assistência Social exerceram influência direta sobre os caminhos tortuosos em direção à integração das áreas sociais (MONNERAT; SOUZA, 2011). Isso torna o elemento conjuntural e os elementos de conformação das áreas de conhecimento atuantes no âmbito de tais políticas aspectos indispensáveis para a análise da implicação dos desafios do processo de intersetorialidade nas referidas políticas públicas no Brasil.

Diante disso, o presente artigo tem como objetivo identificar e discutir os desafios para a intersetorialidade entre as políticas públicas de Saúde e Assistência Social que se evidenciaram no Brasil após a aprovação da Política Nacional de Assistência Social (PNAS) em 2004.

Realizado por meio de revisão bibliográfica, o estudo tem como um primeiro eixo a descrição analítica de produçôes acadêmico-científicas, a fim de investigar quais dimensôes vêm sendo privilegiadas no debate da interação das políticas públicas de Seguridade Social não contributiva no Estado brasileiro. Como segundo eixo, efetuamos a análise temática e interpretativa do material selecionado, com o intuito de discutir os desafios que incidem sobre a efetivação da intersetorialidade entre tais políticas públicas. 
A definição pela abordagem das políticas públicas de assistência social e saúde insere-se no contexto de uma pesquisa maior que busca analisar a proteção básica de assistência social no âmbito da seguridade social. A interlocução específica com a política de saúde é problematizada em função dos desafios comuns que as reúnem em torno da complexa determinação social das condiçóes de vida e saúde da população. Ademais, tais políticas compartilham um desenho de implementação territorializado, articulado por princípios de hierarquização e regionalização de seus respectivos sistemas únicos, o que resulta no fato de que estão em um mesmo território, atendendo a mesma população, ainda que com objetivos específicos diferentes, mas não por isto dissociáveis. A política de saúde, em especial, alcança com a Estratégia de Saúde da Família (ESF) uma significativa capilaridade e capacidade de acompanhamento da população em situação de vulnerabilidade social que poderia tanto ser potencializada, como potencializar a proteção básica de assistência social.

Para buscar elementos que contribuíssem com o debate da questão formulada, este trabalho de abordagem qualitativa, assume, essencialmente, a característica de um estudo do tipo "estado da arte", preocupado com o mapeamento, a descrição e a organização da produçáo vinculada aos desafios para a intersetorialidade nas políticas públicas de Saúde e Assistência Social no Brasil. O tipo de pesquisa "estado da arte" representa uma importante ferramenta metodológica de caráter inventariante e descritivo de produtos acadêmicos e científicos que levam à produção de novos conhecimentos e à reflexão sobre carências e lacunas conceituais (FERREIRA, 2002), assim como proposto neste estudo.

Em um primeiro momento, apresentamos a revisão bibliográfica de produçóes científicas brasileiras que abordaram a intersetorialidade entre as políticas públicas de Assistência Social e Saúde a partir do ano de 2004 até 2017. Ainda que a intersetorialidade esteja prevista na Lei Orgânica da Saúde, instituída em 1990 - Lei no 8.080, o período selecionado privilegia como marco a aprovaçáo da Resolução do Conselho Nacional de Assistência Social - CNAS no 145 de 2004, que instituiu a PNAS, primeira norma legal a explicitar o caráter intersetorial da política pública de Assistência Social. 
O levantamento de produçôes científicas sobre a temática foi realizado por meio de busca no portal da biblioteca eletrônica de periódicos científicos brasileiros SciElo. A definição pela busca na base da SciElo se deveu ao fato de o portal indexar artigos de periódicos das áreas de Saúde Pública e Ciências Sociais, editorados com elevado rigor científico e disponibilizados com acesso aberto em meio eletrônico.

Os produtos foram selecionados a partir de uma primeira busca ampla, realizada em todos os índices e com o descritor "intersetorialidade", retornando 57 artigos. Nas etapas seguintes, houve refinamento da busca. Assim, a primeira busca refinada teve o uso dos descritores "intersetorialidade" AND "desafios". Posteriormente, utilizamos os descritores "intersetorialidade" AND "políticas públicas". Cada fase da busca refinada gerou, respectivamente, 25 e 15 resultados. Do universo de 40 artigos encontrados, 12 foram excluídos segundo os critérios de duplicidade: cinco; publicação em data anterior ao marco de 2004: um, e não abordagem do tema da pesquisa: seis.

Adotou-se a metodologia da análise temática e interpretativa, segundo proposto por Severino (2007), para estudo e problematização dos 28 artigos mapeados. A análise temática dos documentos teve por objetivo promover a apreensão e compreensão objetiva da mensagem global dos estudos selecionados, por meio da síntese das ideias argumentativas dos autores (Severino, 2007). A partir deste ponto, buscamos desenvolver um diálogo com os textos, adotando posicionamentos acerca das ideias expostas ou implícitas nos pressupostos autorais e comparando com outras ideias oriundas de arcabouço teórico pregresso que deu amparo à avaliação crítica, conforme as indicaçôes levantadas da interação com os textos. Com isso, a metodologia mostrou-se adequada para a organização, reflexão e amadurecimento do debate em torno da relevância dos textos para o tema abordado neste estudo.

Com a finalidade de organizar o material para posterior análise, consideramos a área de abordagem de cada estudo após sua leitura flutuante. Este exercício contribuiu para a depreensão de grandes categorias temáticas que direcionaram a análise e discussão dos resultados. As categorias levantadas formam um mosaico de relaçôes que se interpenetram influenciando-se mutuamente, como representado na figura 1 . 


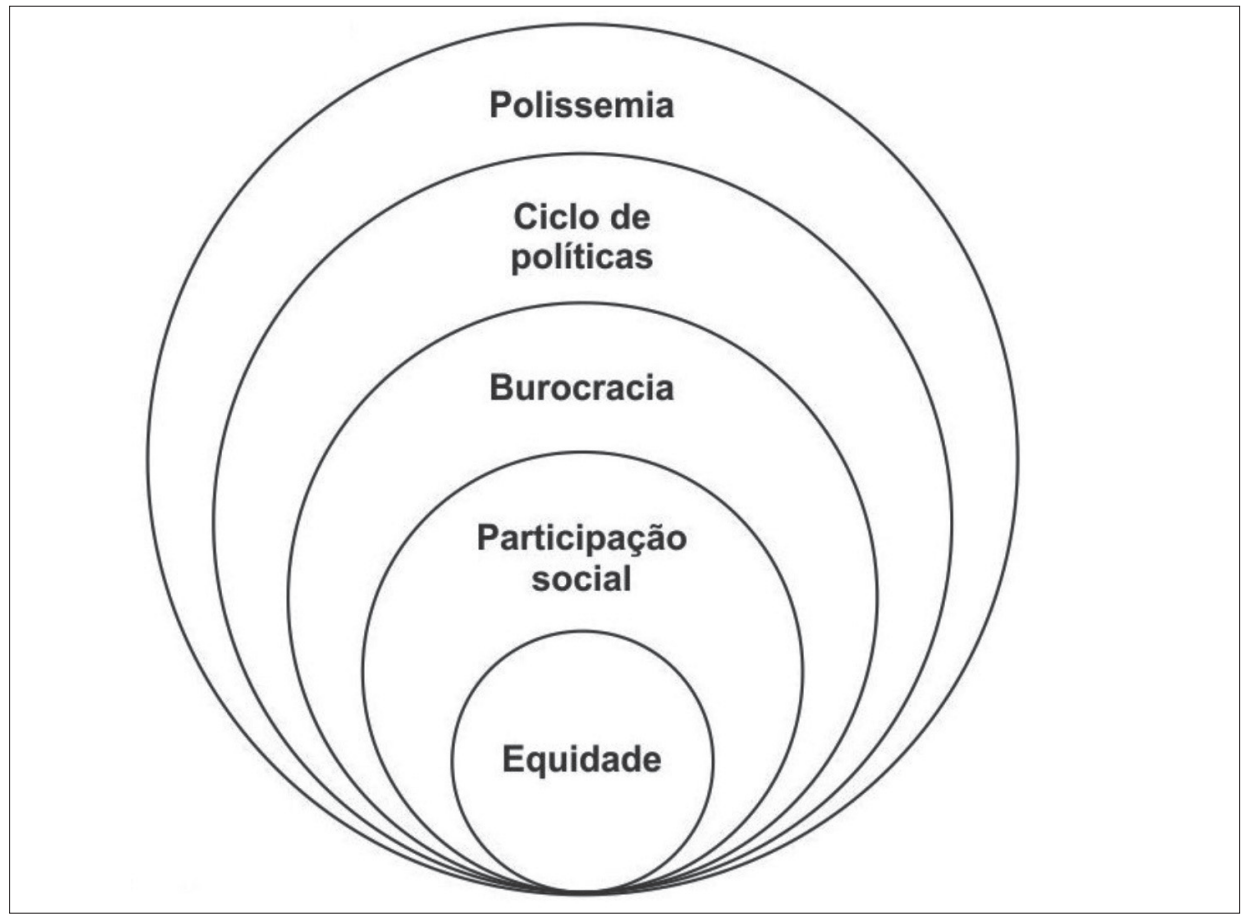

Fonte: Elaboração das autoras.

$\mathrm{Na}$ análise de cada documento, procuramos saliências privilegiadas que poderiam direcionar as investigaçóes e caracterizar conteúdos relevantes quanto à temática da intersetorialidade e implicaçóes dos desafios para sua adoçáo e gestáo nas políticas de Saúde e Assistência Social no Brasil. Para tanto, os documentos foram examinados em sua integralidade, no intuito de revelar tendências, lacunas e deficiências que tocam diretamente na questão dos desafios para a intersetorialidade nas políticas públicas do eixo distributivo da seguridade social brasileira, além de elencar proposiçóes e demandas para pesquisas futuras.

\section{Resultados}

Os resultados quantitativos das buscas estão descritos nas figuras 2 e 3 , a seguir, conforme as grandes áreas de concentração temática dos 28 artigos mapeados. 


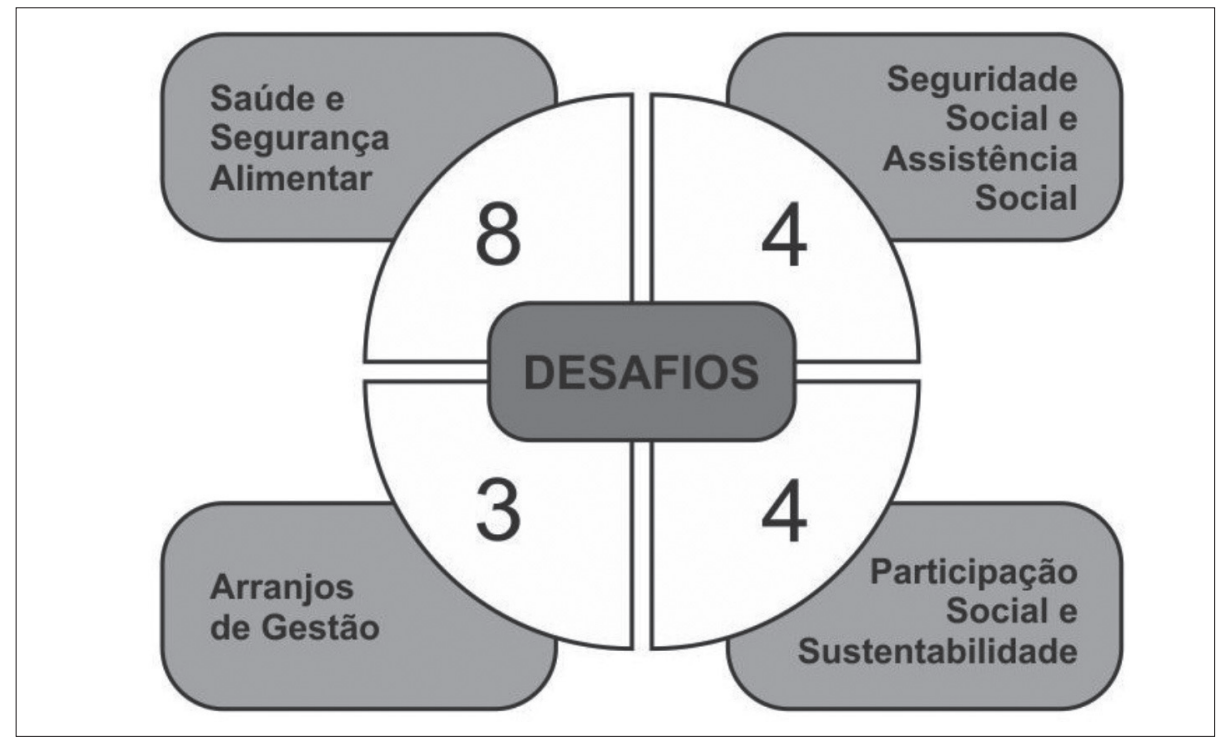

Fonte: Elaboração das autoras.

Os periódicos da área da saúde se destacaram na busca, seguidos por periódicos do serviço social, sociologia, psicologia e administração pública. Foi encontrado maior número de artigos que tratam dos desafios para a prática intersetorial, principalmente no campo da saúde, sendo incluído neste campo 1 artigo (TAVARES et al., 2016) sobre o desafio da formação profissional em saúde. No que diz respeito à abordagem da intersetorialidade no âmbito das políticas públicas, as produções, que se revelaram em menor número global de artigos, também tiveram o campo da saúde como área de maior concentração, abarcando a discussão da formação profissional em um artigo (MELLO; MOYSÉS; MOYSÉS, 2010).

Dada a peculiaridade do tema da formação profissional e sua possibilidade de despertar o olhar diferenciado exigido para o trabalho intersetorial, cabe discorrer sobre os achados nesta área. Os dois estudos mapeados em cada uma das buscas ressaltam a interface entre formação técnico-científica e prática profissional, atentando para a importância da imersão dos discentes no território de vivência das pessoas e do alcance social de pesquisas desenvolvidas no âmbito 
1272 das universidades. Os estudos em questão ainda apontam que o desenvolvimento de competências para solução de problemas multidimensionais pressupóe a habilidade para o diálogo intersetorial. Já a promoção de tais competências e habilidades requer a necessária interlocução entre saúde e educação, sendo as universidades potenciais representantes desta última esfera, como espaço de influências para a promoção da saúde nas comunidades, na perspectiva dos ambientes saudáveis (MELLO; MOYSÉS; MOYSÉS, 2010; ANDRADE, 2004).

Figura 3. Quantidade de artigos da $2^{\mathrm{a}}$ busca com os descritores "intersetorialidade" AND "políticas públicas".

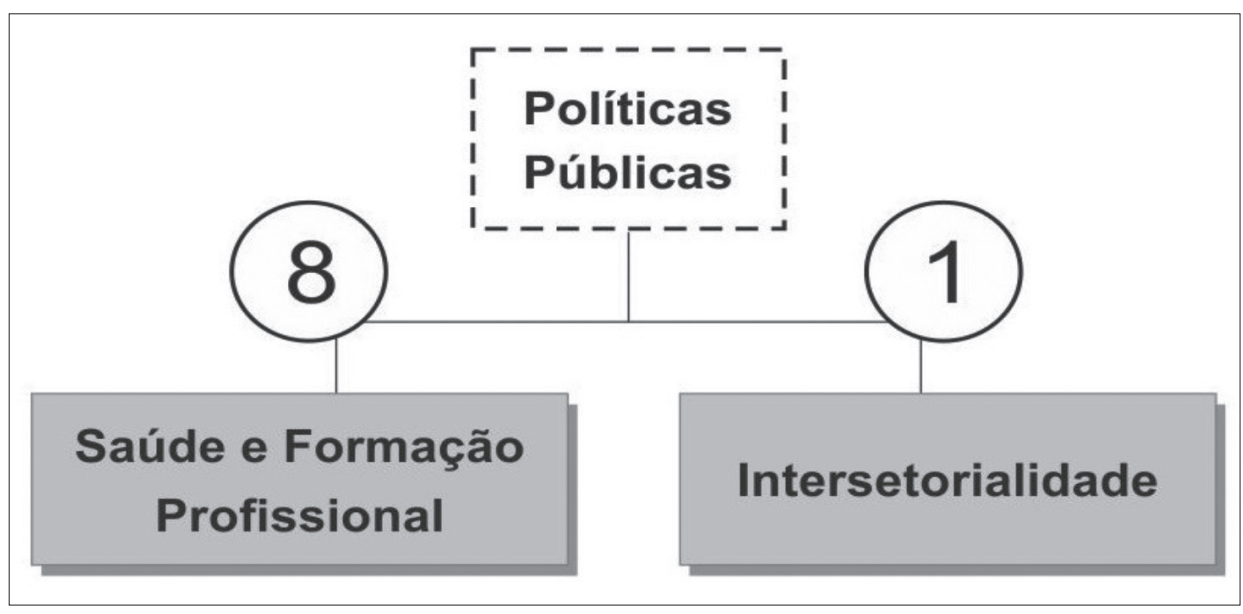

Fonte: Elaboração das autoras.

A maior parte dos trabalhos (24) foi publicada na segunda metade do período em estudo. O interesse pela análise de fenômenos de cunho local (15), seja no nível estadual ou municipal, superou os de cunho nacional (13) no total dos 28 artigos analisados.

Agrupados em outras grandes áreas com o objetivo de organização visual do conteúdo dos estudos, as temáticas: segurança alimentar (BURLANDY, 2009; RIGON, 2016), sustentabilidade (GALLO; SETTI; FARAONI, 2014), e formação profissional (MELLO; MOYSÉS; MOYSÉS, 2010) tiveram abordagem periférica, comparando-se com os demais assuntos predominantes nos artigos. Apenas três artigos abordaram os desafios para a intersetorialidade entre as políticas analisadas neste estudo (MONNERAT; SOUZA, 2011; REZENDE; BAPTISTA; AMÂNCIO FILHO, 2015; VEIGA; BRONZO, 2014). 
Os resultados obtidos apontam uma restrita produção acadêmica sobre a questão da intersetorialidade no país nos últimos 13 anos, o que resulta em poucos cenários para reflexão e elementos para discutirmos os processos em torno das barreiras para sua consecução no âmbito das políticas públicas distributivas da seguridade social brasileira.

\section{Discussão}

O aporte das categorias inferidas com a revisão da literatura permitiu compreender que os desafios para a intersetorialidade entre as políticas públicas de Saúde e Assistência Social no Brasil são semelhantes aos desafios que surgem no âmbito de outras políticas sociais. Assim, resguardadas algumas peculiaridades que envolvem, primordialmente, o processo de institucionalização das políticas analisadas, foi possível transpor a reflexão extraída da revisão do estado da arte para o espaço criado para discutir o eixo distributivo da seguridade social.

Cada tópico desta discussão congrega questóes que se apresentam como desafiadoras para a atuação intersetorial na gestão púbica, mas não são estanques. Ao contrário, reúnem características de situaçôes que se entrelaçam e perpassam o processo de desenvolvimento de políticas públicas de forma amalgamada e sem uma sequência ordenada.

\section{Polissemia como desafio}

A condição de indefinição terminológica é compartilhada por quase todos os conceitos presentes nos grandes temas do campo social. O mesmo se dá em relação ao termo intersetorialidade, que experimenta uma imprecisão teórica nas diferentes áreas do conhecimento que o manejam. A depender do campo disciplinar ao qual se vincula, a intersetorialidade figura-se, ora como estratégia, ora como processo (CAVALCANTI; DANTAS; CARVALHO, 2011), como abordagem ou paradigma (JUNQUEIRA, 2000; BONALUME, 2011). Seja na Saúde Coletiva, na Administração ou na Assistência Social, a polissemia do termo demonstra ainda as diversas correntes de pensamento e discursos em disputa, tais como o institucional, o científico e o da "ponta" do SUAS (MONNERAT; SOUZA, 2011), por exemplo. Nesta perspectiva, a ausência de uma robustez teórica para a conformação da intersetorialidade (AKERMAN, 2014) se faz sentir e leva à consequente imprecisão quanto ao objetivo de sua execução prática. 
Muito recorrente no campo administrativo, sobretudo na corrente dedicada à administração pública, a intersetorialidade pode ser compreendida como uma nova lógica de gestáo para a superação da forma fragmentada com que são executadas as políticas sociais no país (NASCIMENTO, 2010; INOJOSA, 2001; PEREIRA, 2014). Simultaneamente a este entendimento, há a definição de intersetorialidade como forma planejada e integrada de gestão para garantir maior eficiência, eficácia e efetividade e menor gasto de recursos na administração pública (PEREIRA; TEIXEIRA, 2013). Diante de tais esforços de definição, nos amparamos em Nascimento (2010), Schutz e Mioto (2010) e Monnerat e Souza (2011) para defender que a junção dessas ideias não excludentes pode, antes de tudo, se complementar, conferindo maior abrangência e sentido prático ao termo.

Ao incursionarmos pelo ca mpo da saúde, observamos que a atuação intersetorial traz correspondência com o entendimento de Inojosa (2001), Junqueira (2000), Schutz e Mioto (2010) e Nascimento (2010), para quem as políticas setoriais, ainda que não prescindam dos espaços de atuação que lhes são próprios, padecem de uma incompletude inata que favoreceria a atuação intersetorial, não apenas para intercâmbio de saberes, como também para alcance mais profícuo do objetivo de garantia de direitos sociais às populaçóes e mitigação de iniquidades. Contudo, mesmo com a percepçáo do limite da resolutividade setorial a área da saúde, predominantemente, preocupa-se em agir sobre problemas ligados a outros setores (mas que atuam como determinantes do processo saúde-doença, como: falta de saneamento e segurança pública, ausência de política habitacional e educacional etc.), tendo a melhoria dos resultados de saúde da população como horizonte (MONNERAT; SOUZA, 2011). As ações, neste sentido, são pautadas pela orientação da Organização Mundial da Saúde (OMS) em torno da concepção de intersetorialidade (MONNERAT; SOUZA, 2011).

Voltamos à celeuma que envolve o sentido de intersetorialidade reafirmando a pertinência da construção de um arcabouço teórico de sustentação ao conceito, conforme proposto por Akerman (2014). Ao compartilhar com esse autor que o norte de garantia de equidade seria o propósito dos arranjos intersetoriais, acolhemos a concepção de intersetorialidade delineada por Inojosa (2001), que nos parece mais adequada aos objetivos das políticas não contributivas da seguridade social brasileira. Tal concepçáo encontra ressonâncias nos estudos de Veiga e Bronzo (2014), Sposati (2006) e Nascimento (2010). Trata-se de considerar 
intersetorialidade como a articulação entre diferentes saberes e experiências que se integram sinergicamente nas etapas do ciclo das políticas públicas com vistas a atingir patamares de melhor desenvolvimento social (INOJOSA, 2001).

\section{Desafios na burocracia}

A concepção de Inojosa (2001) nos serve para a análise de como os apelos à intersetorialidade são processados dentro do corpo burocrático estatal e o quão refratária tal burocracia pode ser à atuação intersetorial. Compartilhamos da convicção de que intersetorialidade não é algo que ocorre espontânea e naturalmente nas instituiçôes públicas sem provocar resistência e exigir mudanças substanciais no modelo organizacional (PEREIRA; TEIXEIRA, 2013; JUNQUEIRA, 2000). Por isso, o objetivo final de uma política pública comum aos setores envolvidos (INOJOSA, 2001; JUNQUEIRA, 2000) parece ser um caminho para uma atuação intersetorial menos obstaculizada.

Tanto Inojosa (2001) quanto Monnerat e Souza (2011) assentem que o insulamento dos trabalhadores da burocracia estatal é ao mesmo tempo barreira para a intersetorialidade e sintomática da dificuldade para a assunção de postura mais dialógica e interaçóes mais horizontalizadas na gestão pública. Gestores e trabalhadores tendem a fazer um movimento, involuntário ou intencional, de guarda de suas próprias especialidades, bem como de proteção de seu espaço pessoal, garantindo a impermeabilidade de seus setores e de suas possibilidades de relação interpessoal. Esse movimento, acentuado pela assimetria de poder decisório entre os setores governamentais, enseja práticas de corporativismo e resistências, como apontam Feuerwerker e Costa (2000). Como ilustração, vale resgatar Monnerat e Souza (2011) que, a partir de Fleury (2006) e Monnerat e Senna (2007) revelam que o temor pela perda tanto das características específicas quanto da identidade do SUS, levaram a área a, inicialmente, se contrapor à ideia de Seguridade Social.

As mesmas autoras ponderam que, na atualidade, tão claro é o entendimento sobre a apropriação do setor saúde sobre os resultados esperados com a atuação intersetorial que a Organizaçáo Panamericana da Saúde (OPAS) recomenda que a intersetorialidade em saúde seja tanto a iniciativa quanto o aceite do setor para a integração (MONNERAT; SOUZA, 2011 APUD COSTA, 2006). 
O trabalho intersetorial transcende a lógica do mero trabalho em conjunto. Pressupõe não só troca de saberes em ação interdisciplinar como a atuação sinérgica em torno de um objetivo comum, requerendo habilidades e competências que não são tradicionalmente desenvolvidas ou estimuladas na burocracia estatal nem anteriormente, na formação acadêmico-profissional deste corpo técnico (MOYSÉS; MOYSÉS; KREMPEL, 2004).

Uma mudança paradigmática na direção intersetorial não pressupóe preterir as disciplinas em suas singularidades, e sim ensejar um processo comunicacional, não só para ressignificar as práticas na gestão pública, mas também enriquecer a compreensão das diferenças de saberes. A setorialidade, portanto, não é necessariamente suprimida pela intersetorialidade, já que os domínios disciplinares devem ser sintetizados através da comunicação (INOJOSA, 2001; SCHUTZ; MIOTO, 2010; LIMA; VILASBÔAS, 2011).

\section{Desafiando o ciclo de políticas públicas}

A abordagem tradicional do ciclo de políticas públicas trata de "um esquema de visualização e interpretação que organiza a vida de uma política pública em fases sequenciais e interdependentes" (SECCHI, 2010, p. 33), sendo as principais: Identificação do Problema, Formação da Agenda, Formulação de Alternativas, Tomada de Decisão, Implementação, Avaliação e Extinção. Por outro lado, Secchi (2010) pondera que o esquema tradicional do ciclo de políticas públicas tem mais sucesso na utilização com fins didáticos do que com a pretensão de representar um processo que, na realidade, não possui fases com limites demarcados nem sequência linear de ocorrência. A partir da ponderação desse autor, compreendemos junto com Veiga e Bronzo (2014), Lotta e Favareto (2016), ancorados nos estudos trazidos por Ball (REZENDE; BAPTISTA, 2015), que o processo de uma política pública é menos cíclico que contextual.

É nítida, na literatura, a abordagem preponderante da atuação intersetorial na fase de implementação das políticas públicas. Todavia, vêm ganhando espaço abordagens que privilegiam outras fases do ciclo de políticas públicas como propensas ao desenvolvimento de açôes intersetoriais, conforme vemos em Magalhães (2004), citado por Veiga e Bronzo (2014). Mas, de forma análoga às demandas e necessidades multifacetadas e não lineares das populações em seus territórios, as políticas públicas se constituem em ambientes reais, que sofrem 
influências de atores distintos, internas e externas, conjunturais e estruturais.

Por isso, faz mais sentido falar que as fases das políticas públicas não obedecem a uma sequência hierárquica, mas se inter-relacionam, e que, assim, a atuação intersetorial caberia em qualquer momento, a critério do resultado esperado. Decorre dessas análises a adoção, nesta pesquisa, de Stephen Ball como referência para a abordagem do ciclo de políticas públicas.

Prisco (2012), ao organizar a intersetorialidade a partir de três dimensóes que lhe são próprias - quais sejam, gerencial; técnica; participativa ou popular aproxima-se da noção trazida por Stephen Ball sobre os contextos onde se dariam as políticas públicas, quais sejam: contexto da influência - ação política a partir da relação entre grupos de interesse; contexto da produção de textos - em que os textos das políticas são produzidos; e contexto da prática - quando são tomadas decisôes e traçadas estratégias de ação para solucionar questóes institucionais e políticas (REZENDE; BAPTISTA, 2015). O desafio, nesse prisma, é definir de modo mais explícito os objetivos pretendidos e descobrir como trabalhar as influências de cada contexto, reconhecendo os momentos em que as diferentes dimensôes da intersetorialidade estarão mais presentes. A partir daí, cremos ser possível identificar em que situaçôes as políticas públicas devem agir setorialmente ou quando e por qual motivo devem integrar-se. Nesta direção, fazemos um contraponto a um conjunto de autores (LIMA; VILASBÔAS, 2011, MOYSÉS; MOYSÉS; KREMPEL, 2004) para quem a fase do planejamento seria a maneira mais eficaz de construir articulaçóes sobre objetivos comuns de trabalho.

As fontes literárias mostram existir uma tendência à associação da prática da intersetorialidade a um melhor desempenho na oferta de alguns serviços públicos que não apresentariam melhora se fossem executados de forma não articulada (CUNILL-GRAU, 2016). Entretanto, outras correntes literárias levantam críticas sobre o apelo insistente para a centralidade da ação intersetorial como grande promessa no quesito da gestão em políticas de seguridade social (BIDARRA, 2009; PEREIRA; TEIXEIRA, 2013).

A ação direcionada pela perspectiva intersetorial em nada se assemelha às ações em que trabalhos setoriais são executados de forma justaposta (INOJOSA, 2001). Acreditar que a intersetorialidade incide sobre a efetivação da ação pública como consequência do trabalho processual e complementar de projetos, mais do que de um conjunto de projetos que se comunicam em alguma etapa de 
sua implementação (INOJOSA, 2001), nos permite somar que a comunicação é essencial (AKERMAN, 2014; LIMA; VILASBÔAS, 2011) para corrigir distorçôes, bem como alinhar e clarificar entendimentos (MAGALHÃES et al., 2011). Além disso, a comunicação é favorecida quando ocorre em qualquer etapa do ciclo da política - preferencialmente com a participação da sociedade civil.

\section{Participação desafiadora}

As políticas públicas distributivas de seguridade social estão organizadas cada qual por meio de sistema único, descentralizado e participativo. Assim, os sistemas SUAS e o SUS possuem, dentre suas diretrizes, a participação da população organizada por meio de representaçôes na gestão dos sistemas nas três esferas de governo, tanto na formulação quanto no controle social das açóes das políticas (BRASIL, 1990; 1993).

Pereira e Teixeira (2013), bem como Cunill-Grau (2016) e Monnerat e Souza (2011) introduzem um outro ator nas reflexôes sobre o processo da atuação intersetorial: a sociedade civil. As autoras aludem à relação entre setores governamentais e não governamentais, distinguindo-se nestes últimos, as comunidades (PEREIRA; TEIXEIRA, 2013; CUNILL-GRAU, 2016). Em consonância com tais autoras, Comerlato et al. (2007) debruçam-se sobre os desafios da intersetorialidade quando entendida como processo de governança que permite participação popular e controle social no desenho das políticas públicas.

A partir desses apanhados, consideramos que a sociedade civil é parte constituinte das políticas públicas, não apenas por se configurar como público destinatário e força de trabalho das políticas, mas, sobretudo, por ser potencial parceira na definição das açôes de tais políticas e de sua fiscalização.

Monnerat e Souza (2011) destacam que a baixa institucionalidade da política de assistência social aliada à frágil organização de seus trabalhadores e público usuário contribuem para a também frágil legitimação social da política. Em oposição, mas sem perder de vista a contribuição de diferentes atores na luta pela regulamentação da política de assistência social no Brasil, a política de saúde traz um histórico mais longo e acentuado de consolidação, haja vista a previsão constitucional de participação da comunidade na gestão do SUS, regulamentada desde o início da década de 1990 pela Lei no 8.080 (BRASIL, 2016; 1990). Entretanto, ambas as políticas experimentam a dificuldade de 
integração entre seus conselhos (COMERLATO et al., 2007), o que desfavorece

a pressão constante por ampliação de espaços de participação, diminuindo as chances de influência popular no processo de desenvolvimento das políticas não contributivas da seguridade social.

Estas observaçôes apontam para a importância do trabalho integrado entre setores governamentais e sociedade para examinar que interesses sustentam tal parceria e qual seu papel no modelo de Estado que faz ofertas públicas com vistas à redução de vulnerabilidades sociais, respeito aos seus usuários e garantia de equidade no usufruto de direitos.

O debate atual pauta a intersetorialidade como ferramenta essencial para um diálogo mais efetivo entre as políticas sociais, no sentido de conferir cobertura mais integral às demandas postas pela sociedade - demandas que não se apresentam de forma setorizada, mas são atendidas como tal pelo poder público. Indica também uma abordagem da população com base nos diversos aspectos de sua vida, em sua dimensão integral (PEREIRA; TEIXEIRA, 2013; SCHUTZ; MIOTO, 2010), o que se refere à intersetorialidade como algo que extrapola conceitualmente o campo das políticas sociais para conectar-se com as demais relaçôes estabelecidas entre as pessoas nos seus territórios. $\mathrm{O}$ desafio seria, ainda, incorporar à agenda pública as demandas vocalizadas pelos próprios interlocutores.

\section{O desafio dos fins e dos meios}

A marca da intersetorialidade como indutora de superação da fragmentação nas políticas sociais orienta para uma ideia de colaboração, de complementaridade, promovendo um olhar atento às necessidades das populaçóes, reconhecendo as particularidades de sua organização, suas formas de sobrevivência e os rebatimentos da questão social em seu cotidiano. A atuação intersetorial possibilita o acionamento articulado dos conhecimentos próprios de políticas distintas (JUNQUEIRA, 2000) para dar conta da complexidade das demandas vivenciadas pela população.

O olhar inovador, contudo, coexiste com formas renovadas de conservadorismo no enfrentamento da questão social, seja na oferta de serviços ou na forma de gerir a "coisa pública". Desta afirmação retiramos como exemplo as práticas assistencialistas e com finalidade eleitoral que se travestem de serviço público em açóes das políticas de assistência social e saúde quando praticadas por trabalhadores ou agentes em mandatos políticos. 
Todo potencial de trabalho integrado entre as políticas de saúde e assistência social sofre inflexôes pela baixa legitimidade social e política e pela fragilidade institucional. $\mathrm{O}$ caminho que as políticas públicas não contributivas da seguridade social seguiram após sua inclusão na Constituição de 1988, de acordo com Monnerat e Souza (2011), não oportunizou seu fortalecimento institucional, nem a abertura do quadro de especialistas que formavam seu corpo técnico. As mesmas autoras apontam ainda, ao citar Giovannella et al. (2002) e Mattos (2001), que há uma relação proporcional entre a falta de priorização do desenvolvimento da diretriz da integralidade no SUS e a baixa articulação da política de saúde com outras políticas setoriais nas duas últimas décadas.

São essas as características que deram continuidade à fragmentação da forma de atuar que se tornou típica no âmbito das políticas sociais. Descendem deste quadro as relaçóes intersetoriais construídas informalmente, com base nas relaçóes pessoais, de amizade, com pouca perspectiva de concretude e durabilidade - o que vai na contramão da concepção de direito que as políticas analisadas buscam afirmar.

A gestão pública incrementada pelos arranjos intersetoriais náo ilude a respeito da maior solução de problemas na administração, conforme nos alerta Akerman (2014). As práticas subalternizantes atravessam as ofertas públicas e sua extirpação é processual, dependente de aprofundamento democrático e mudanças culturais. Ainda assim, acreditamos que a própria atuação intersetorial, incluindo o entendimento da sociedade civil como partícipe, oferece elementos de potencial ruptura com essas práticas reforçadoras de desigualdades.

\section{Considerações finais}

O objetivo da redução de vulnerabilidades e garantia de usufruto de direitos com equidade pressupõe uma orientação da oferta pública de serviços na direção do aumento de proteção social. A polissemia do termo intersetorialidade, mesmo no interior das políticas de assistência social e saúde (MONNERAT; SOUZA, 2014; PEREIRA; TEIXEIRA, 2013), revela necessidades de se investigar em qual proporção os projetos vigentes dizem respeito à efetivação de uma proposta de articulação intersetorial sinérgica que envolva compartilhamento de saberes para um objetivo comum (NASCIMENTO, 2010). 
Intersetorialidade é um conceito ainda sem consenso teórico e por isso em construção (SPOSATI, 2006). É justamente esta característica inacabada que estimula a realização de estudos acerca dos desafios, limites e potenciais da intersetorialidade entre as políticas públicas de assistência social e saúde, tendo em vista a melhoria, em sentido amplo, da qualidade de vida de indivíduos, famílias e comunidades em seus territórios como direito sem contrapartida financeira.

Corresponde à nossa compreensáo a ideia de que a intersetorialidade, como consequência e produto da articulação de diferentes conhecimentos (INOJOSA, 2001), é apreendida como um novo processo na dinâmica governamental para o alcance de resultados integrados, sem perder de vista a dimensão do planejamento e da avaliação em políticas públicas permeados pela participação da sociedade civil. $\mathrm{E}$, nesse sentido, constitui ferramenta institucional de qualificação das ofertas estatais frente às manifestaçóes cada vez mais complexas da questão social, já que acrescenta, como dimensão analítica, arranjos interdisciplinares para induzir (ALMEIDA; SANTOS, 2014) e promover apreensóes das demandas sociais apoiando-se no princípio da integralidade e na diretriz da participação popular. Nisso reside seu papel de superar fragmentações, não só na estrutura do aparato estatal, mas também no campo do conhecimento, dentro das ciências sociais, superando práticas assistencialistas e de gestão fragmentárias.

Neste contexto, grassa nossa suposição de que a intersetorialidade entre políticas públicas de seguridade social de natureza não contributiva é, pois, um modelo de gestáo ao qual a realização da integralidade e da equidade se liga organicamente. Contudo, se naturalizarmos de maneira inquestionável a correspondência entre intersetorialidade e integralidade/equidade, desconsideraremos os obstáculos à realização de reflexôes em torno dos diferentes modos e conexôes possíveis e necessários para a existência da intersetorialidade. Assim, ao atuar no âmbito das políticas públicas em questão, cabe refletir sobre qual resultado se pretende obter com a adoção deste paradigma/processo/modo de gestão. Além disso, importa pensar sobre qual concepçáo de intersetorialidade nos vinculamos; como lidar com as resistências dos trabalhadores; como garantir maior participação e controle social; como fazer a gestão, a avaliaçáo e o monitoramento das açôes intersetoriais com vistas ao alcance de maior integralidade e equidade nas ofertas públicas das políticas em foco. 
Diante do que discorremos, consideramos que é premente maior integração entre as políticas públicas analisadas, sendo a intersetorialidade fundamental estratégia para intensificar resultados no âmbito social e da saúde. Cremos que a problemática falta de estudos aprofundados sobre intersetorialidade e sua acepção em sentido lato, bem como maior ênfase sobre os desafios para sua consecução, é destacada como entrave às postulações acerca da sua construção e aporte para trabalhar com o horizonte da transformação social. Ademais, são justamente essas compreensões que podem impulsionar não só a realização de estudos nesse sentido, como a adoção de posturas mais permeáveis à atuação intersetorial e à participação da sociedade civil no desenho das políticas públicas de assistência social e saúde, com vistas a torná-las, de fato, distributivas. ${ }^{1}$

\section{Referências}

AKERMAN, M. et al. Intersetorialidade? IntersetorialidadeS! Ciência \& Saúde Coletiva. Rio de Janeiro, v. 19, n. 11, p. 4291-4300, 2014. Disponível em: <http://www.scielo.br/pdf/ csc/v19n11/1413-8123-csc-19-11-4291.pdf>. Acesso em: 25 maio 2016.

ALMEIDA, G.; SANTOS, M. C. B. Intersetorialidade na efetivação do processo transexualizador do SUS: uma indispensável utopia. In: MONNERAT, G. L. et al. (Org.). A intersetorialidade na agenda das politicas sociais. Campinas: Papel Social, 2014. p. 203-227. ANDRADE, L. O. M. de. A saúde e o dilema da intersetorialidade. 2004. Tese (Doutorado - Programa de Pós-Graduaçáo em Saúde Coletiva) - Universidade Estadual de Campinas, Campinas, 2004. Disponível em: <http://www.bibliotecadigital.unicamp.br/document/?co $\mathrm{de}=\mathrm{vtl}$ 0000376076\&fd=y>. Acesso em: 8 maio 2016.

BIDARRA, Z. S. Pactuar a intersetorialidade e tramar as redes para consolidar o sistema de garantia de direitos. Serviço Social e Sociedade. São Paulo, v. 99, p. 483-497, jul-set. 2009.

BOSCHETTI, Ivanete. Implicaçôes da reforma da previdência na seguridade social brasileira. Psicologia \& Sociedade. Belo Horizonte, v. 15, n. 1, p. 57-96, jan-jun.2003.

BONALUME, Cláudia Regina. O Paradigma da Intersetorialidade nas Políticas Públicas de Esporte e Lazer, Licere. Belo Horizonte, v. 14, n. 1, mar. 2011. Disponível em: <https:// seer.ufmg.br/index.php/licere/article/viewFile/511/403>. Acesso em: 12 abr. 2017.

BRASIL. Constituição da República Federativa do Brasil, 8 de outubro de 1988. Brasília, DF: Senado Federal, Coordenação de Edições Técnicas, 2016. 496 p.

Lei no 8.080, de 19 de setembro de 1990. Dispóe sobre as condiçóes para a promoçấo, proteçâo e recuperação da saúde, a organização e o funcionamento dos serviços correspondentes e dá outras providências. Diário Oficial da União, Brasília, DF, 19 set. 1990 a. Seção 1 . 
. Lei no 8.142 , de 28 de dezembro de 1990. Dispóe sobre a participação da comunidade

na gestão do Sistema Único de Saúde (SUS) e sobre as transferências intergovernamentais de recursos financeiros na área da saúde e dá outras providências. Diário Oficial da União. Brasília, DF, 31 dez. 1990 b. Seção 1.

Presidência da República. Lei Orgânica da Assistência Social, no 8.742, de 7 de setembro de 1993.

BURLANDY, L. A construção da política de segurança alimentar e nutricional no Brasil: estratégias e desafios para a promoção da intersetorialidade no âmbito federal de governo. Ciência \& Saúde Coletiva. Rio de Janeiro, v. 14, n. 3, p. 851-860, jun. 2009.

CAVALCANTI, P. B.; DANTAS, A. C. da S.; CARVALHO, R. N. Contornos e sinergias entre a política de Saúde e o adolescente privado de liberdade: intersetorialidade como desafio. Revista Textos \& Contextos, v. 10, n. 2, p. 399-410, 2011. Disponível em: <http://revistaseletronicas. pucrs.br/ojs/index.php/fass/article/viewArticle/9346>. Acesso em: 29 abr. 2016.

COMERLATTO, D. et al. Gestão de políticas públicas e intersetorialidade: diálogo e construçóes essenciais para os conselhos municipais. Revista Katálysis. Florianópolis, v. 10, n. 2, p. 265-271, jul/dez. 2007.

CUNILL-GRAU, N. A intersetorialidade nas novas políticas sociais: uma abordagem analítico-conceitual. In: BRASIL. Ministério do Desenvolvimento Social e Combate à Fome. Secretaria de Avaliação e Gestão da Informação. Cadernos de Estudos Desenvolvimento Social em Debate: Intersetorialidade nas políticas sociais: perspectivas a partir do Programa Bolsa Família. Brasília: MDS, 2016. n. 26, p. 35-66. Disponível em: <http://aplicacoes. mds.gov.br/sagirmps/ferramentas/docs/Caderno\%20de\%20Estudos\%2026.pdf>. Acesso em: 5 maio 2016.

FERREIRA, N. S. de A. As pesquisas denominadas “estado da arte". Educação \& Sociedade. Campinas, v. 23, n. 79, p. 257-272, ago. 2002.

FEUERWERKER, L. C. M.; COSTA, H. Intersetorialidade na rede UNIDA. Divulgação em Saúde para Debate. Londrina, n. 22, p. 25-35, dez. 2000.

GALLO, E.; SETTI, A. F. F. Território, intersetorialidade e escalas: requisitos para a efetividade dos Objetivos de Desenvolvimento Sustentável. Ciência \& Saúde Coletiva. Rio de Janeiro, v. 19, n. 11, p. 4383-4396, nov. 2014.

INOJOSA, R. M. Sinergia em políticas e serviços públicos: desenvolvimento social com intersetorialidade. Cadernos Fundap. São Paulo, n. 22, p. 102-110, 2001. Disponível em: <http://www.pucsp.br/prosaude/downloads/bibliografia/sinergia_politicas_servicos_ publicos.pdf>. Acesso em: 4 maio 2016.

JUNQUEIRA, L. A. P. Intersetorialidade, transetorialidade e redes sociais na saúde. Revista de Administração Pública. Rio de Janeiro, v. 34, n. 6, p. 35-45, nov/dez. 2000. Disponível em: <http://bibliotecadigital.fgv.br/ojs/index.php/rap/article/viewFile/6346/4931>. Acesso em: 24 maio 2016. 
LIMA, E. C. de; VILASBÔAS, A. L. Q. Implantação das açôes intersetoriais de mobilização social para o controle da dengue na Bahia, Brasil. Cadernos de Saúde Pública. Rio de Janeiro, v. 27, n. 8, p. 1507-1519, ago. 2011.

LOTTA, G.; FAVARETO, A. Desafios da integração nos novos arranjos institucionais de políticas públicas no Brasil. Revista de Sociologia e Política. Curitiba, v. 24, n. 57, p. 49-65, mar. 2016.

MAGALHÃES, R. et al. Intersetorialidade, convergência e sustentabilidade: desafios do programa Bolsa Família em Manguinhos, RJ. Ciência \& Saúde Coletiva. Rio de Janeiro, v. 16, n. 11, p. 4442-4453, nov. 2011.

MELLO, A. L. S. F. de; MOYSÉS, S. T.; MOYSÉS, S. J. A universidade promotora de saúde e as mudanças na formação profissional. Interface. Botucatu, v. 14, n. 34, p. 683-692, set. 2010.

MONNERAT, G. L., SOUZA, R. G. de. Política social e intersetorialidade: consensos teóricos e desafios práticos. Revista SER Social. Brasília, v. 12, n, 26, p. 200-220, jan/ jun. 2009. Disponível em: <http://www.periodicos.unb.br/index.php/SER_Social/article/ viewFile/1023/683>. Acesso em: 31 maio 2016.

- Da Seguridade Social à intersetorialidade: reflexóes sobre a integração das políticas sociais no Brasil. Revista Katálysis. Florianópolis, v. 14, n. 1, p. 41-49, jan/jun. 2011. Disponível em: <http://www.scielo.br/pdf/rk/v14n1/v14n1a05.pdf>. Acesso em: 15 abr. 2016.

Intersetorialidade e Políticas Sociais: um diálogo com a literatura atual. In: MONNERAT, G. L.; ALMEIDA, N. L. T.; SOUZA, R. G. de. (Org.). A intersetorialidade na agenda das politicas sociais. Campinas: Papel Social, 2014. p. 41-54.

MOYSÉS, S. J.; MOYSÉS, S. T.; KREMPEL, M. C. Avaliando o processo de construção de políticas públicas de promoção de saúde: a experiência de Curitiba. Ciência \& Saúde Coletiva. Rio de Janeiro, v. 9, n. 3, p. 627-641, jul-set. 2004.

NASCIMENTO, S. do. Reflexôes sobre a intersetorialidade entre as políticas públicas. Serviço Social \& Sociedade. São Paulo, n. 101, p. 95-120, 2010.

PEREIRA, K. Y. de L.; TEIXEIRA, S. M. Redes e intersetorialidade nas políticas sociais: reflexôes sobre sua concepção na política de assistência social. Revista Textos \& Contextos. Porto Alegre, v. 12 n. 1, p. 114-127, 2013. Disponível em: <http://revistaseletronicas.pucrs. br/ojs/index.php/fass/article/view/12990/9619>. Acesso em: 24 maio 2016.

PEREIRA, P. A. P. A intersetorialidade das políticas sociais na perspectiva dialética. In: MONNERAT, G. L.; ALMEIDA, N. L. T.; SOUZA, R. G. de. (Org.). A intersetorialidade na agenda das políticas sociais. Campinas: Papel Social, 2014. p. 21-39.

. A Saúde no sistema de seguridade social brasileiro. Ser Social, Brasília, v. 10, n. 10, p. 33-55. jan/jun. 2002 Disponível em: <http://repositorio.unb.br/bitstream/10482/7276/1/ ARTIGO_SaudeSistemaSeguridade.pdf>. Acesso em: 08 mar. 2017. 
PRISCO, T. Assistência social: A política pública (inter)setorial. Revista Gestão \& Políticas

Públicas. São Paulo, v. 2, n. 1, p.134-149, 2012. Disponível em: <http://www.revistas.usp. br/rgpp/article/view/97854>. Acesso em: 23 fev. 2017.

REZENDE, M. de; BAPTISTA, T. W. de F. A Análise da Política Proposta por Ball. In: MATTOS, R. A. de; BAPTISTA, T. W. de F. (Org.). Caminhos para análise das políticas de saúde. 1. ed. Porto Alegre: Rede UNIDA, 2015. 509 p. (Série Interlocuções. Práticas, experiências e pesquisas em saúde). p. 273-283.

REZENDE, M. de; BAPTISTA, T. W. de F.; AMÂNCIO FILHO, A. O legado da construção do sistema de proteção social brasileiro para a intersetorialidade. Trabalho Educação Saúde. Rio de Janeiro, v. 13, n. 2, p. 301-322, ago. 2015.

RIGON, S. do A.; SCHMIDT, S. T.; BÓGUS, C. M. Desafios da nutrição no Sistema Único de Saúde para construção da interface entre a saúde e a segurança alimentar e nutricional. Cadernos de Saúde Pública. Rio de Janeiro, v. 32, n. 3, 2016.

SCHUTZ Fernanda; MIOTO, Regina Célia Tamaso. Intersetorialidade e política social: subsídios para o debate. Sociedade em Debate, Pelotas, v. 16, n. 1, p. 59-75, jan-jun. 2010. Disponível em: <http://revistas.ucpel.tche.br/index.php/rsd/article/view/337/295>. Acesso em: 30 abr. 2016.

SECCHI, L. Políticas públicas: conceitos, esquemas de análise, casos práticos. São Paulo: Cengage Learning, 2010. 133p.

SEVERINO, A. J. Metodologia do Trabalho Cientifico. São Paulo: Saraiva, 2007.

SPOSATI, A. Gestão pública intersetorial: sim ou não? Comentários de experiência. Serviço Social e Sociedade. São Paulo, n. 85, p. 133-141, mar. 2006.

TAVARES, M. de F. L. et al. A promoção da saúde no ensino profissional: desafios na Saúde e a necessidade de alcançar outros setores. Ciência \& Saúde Coletiva. Rio de Janeiro, v. 21, n. 6, p. 1799-1808, jun. 2016.

VEIGA, L. da; BRONZO, C. Estratégias intersetoriais de gestão municipal de serviços de proteção social: a experiência de Belo Horizonte. Revista de Administraçâo Pública. Rio de Janeiro, v. 48, n. 3, p. 595-620, maio-jun. 2014.

\section{Nota}

${ }^{1}$ M. E. Carmo foi responsável pela concepção, análise e interpretação dos dados, e redação do artigo. F. L. Guizardi colaborou na concepção, revisão crítica relevante do conteúdo intelectual e aprovação da versão final a ser publicada. 


\section{Abstract}

\section{Challenges of intersectoriality in public health and social assistance policies: a review of the state of the art}

Intersectoriality is a much-discussed topic, but not the challenges for its implementation between public health policies and social assistance. With the revision of the state of the art of the theme, we discuss in this article the main challenges of intersectoral work among such policies. The categories polysemy, policy cycle, bureaucracy, social participation and equity guide the debate with the method of interpretive analysis. Although it can respond to the multifaceted social demands, avoiding damages of the sectoral fragmentation, the intersectoriality is not solution for every problem of public management. However, its relationship with popular participation may confer greater equity in the proposals of the analyzed policies.

> Keywords: intersectoriality; health; social assistance; challenges; equity. 